\title{
BACEM (BAHAN BAKAR CEMPEDAK) : INOVASI KULIT CEMPEDAK MENJADI BIOETANOL SEBAGAI BAHAN BAKAR ALTERNATIF
}

\author{
Dea Amalia Ramadhanty \\ Program Studi Pendidikan Kimia FKIP Universitas Sebelas Maret \\ deaamaliaramadhanty@gmail.com
}

\begin{abstract}
ABSTRAK
Penggunaan bahan bakar fosil dewasa ini semakin tidak terkendali. Permintaan akan bahan bakar yang banyak, tidak diimbangi dengan penyediaan dan pengelolaan yang tepat. Oleh karena itu, diperlukan bahan alternatif lain yang mampu mengurangi pemakaian bahan bakar fosil agar kelestarian bumi tetap terjaga. Penelitian terdahulu yang memanfaatkan kulit nangka menjadi bioetanol menjadi pencetus awal ide untuk mengganti kulit nangka dengan kulit cempedak (Artocarpus champeden) karena karateristik kulitnya yang hampir sama. Prinsip dari pembuatan bioetanol berbahan dasar kulit cempedak ini menggunakan proses fermentasi dengan bantuan mikroba Saccharomyces cerevisiae. Hasil dari pemanfaatan ini adalah bioetanol berbahan dasar kulit cempedak dengan kadar rendah yang dapat menjadi campuran bahan bakar konvensional. Campuran ini memiliki keunggulan yaitu dalam peningkatan performa mesin. Luaran yang dihasilkan juga diharapkan mampu menjadi bahan bakar alternatif sebagai pengganti bahan bakar fosil saat ini.
\end{abstract}

Kata Kunci: cempedak, fermentasi, Saccharomyces cerevisiae

\section{PENDAHULUAN}

Keberadaan bahan bakar khususnya yang berasal dari fosil saat ini sungguh memprihatinkan. Jumlahnya yang sudah tidak sebanyak dulu terkadang tidak bisa mengimbangi kebutuhan masyarakat yang dapat dikatakan sangat banyak. Bahan bakar fosil menjadi penggerak utama dalam hal mobilitas, kebutuhan dapur, hingga dalam skala besar sebagai bahan bakar mesin-mesin pada pabrik. Belum lagi ditambah waktu yang dibutuhkan untuk terbentuknya bahan bakar fosil ini tidak singkat. Tentu diperlukan peran serta kesadaran masyarakat dalam menjaga kelestariannya yang dapat dilakukan dengan banyak cara. Salah satu terobosan yang akan dipaparkan dalam karya ilmiah ini yaitu pemanfaatan limbah yang digunakan dalam pembuatan bioetanol sebagai pengganti bahan bakar fosil. Limbah yang digunakan merupakan limbah hayati yang dapat berasal dari tumbuhan apa saja. Pemanfaatan limbah menjadi bahan bakar alternatif ini dapat meningkatkan dari sisi ekonomi yaitu meningkatkan harga jualnya sekaligus dapat menjadi solusi yang membantu menjaga kelestarian bumi dan keberadaan bahan bakar fosil.

Cempedak (Artocarpus champeden) merupakan buah yang banyak tumbuh di daerah tropis dan menjadi buah khas pulau Kalimantan. Cempedak atau 
yang biasa disebut tiwadak oleh masyarakat lokal ini memiliki banyak manfaat yang terkandung di dalamnya. Selain daging buahnya, hampir semua bagian cempedak dapat dimanfaatkan, seperti batang, biji, bahkan hingga kulitnya. Di daerah asalnya, yaitu di Kalimantan sendiri kulit cempedak sering disajikan menjadi santapan dalam bentuk asinan yang diberi nama mandai. Bahan bakar cempedak (Bacem) merupakan bentuk lain dari pemanfaatan kulit cempedak yang dapat menjadi alternatif pengganti bahan bakar fosil yang tak terbarukan.

Bioetanol merupakan hasil dari fermentasi karbohidrat atau selulosa yang tersusun atas kandungan glukosa dengan bantuan mikroba (Khairani, 2007). Fermentasi sendiri merupakan proses penguraian senyawa organik untuk menghasilkan suatu energi serta proses pengubahan substrat menjadi produk oleh mikroba dalam keadaan anaerob (Madigan dkk., 2008). Mikroba yang digunakan pada penelitian ini yaitu Saccharomyces cerevisiae, mikroba ini dipilih karena memiliki beberapa kelebihan diantaranya jumlahnya yang tergolong banyak, mudah ditemukan, daya tahan hidupnya yang tinggi, dan kemampuannya untuk menghasilkan etanol dalam jumlah dan kadar yang cukup banyak (Jeffries dan Jin, 2000). Bahan baku dari pembuatan bioetanol dapat diambil dari pemanfaatan limbah dari hasil pertanian yang bernilai ekonomi rendah (Novia dkk., 2014). Bioetanol memiliki keunggulan yaitu dapat mengurangi emisi gas karbon dioksida hingga 18\%, ramah lingkungan, hingga kemampuannya dalam meningkatkan performa mesin yang tidak perlu diragukan.

Pembuatan bioetanol dari kulit cempedak ini akan diawali dengan proses penyaringan filtrat dari kulit cempedak yang sebelumnya telah dibersihkan arinya dan dipotong kecil yang kemudian akan difermentasikan dengan bantuan mikroba Saccharomyces cerevisiae. Pada proses ini diperlukan optimalisasi lingkungan tumbuh mikroba selama fermentasi agar sesuai dengan habitat tumbuh bagi mikroba yang digunakan. S. cerevisiae tumbuh baik pada suhu $30^{\circ} \mathrm{C}$ dengan $\mathrm{pH}$ optimum antara 4,5-5,0. Optimalisasi penting dilakukan guna menghasilkan etanol yang berkualitas.

Penelitian ini bertujuan untuk mengetahui proses produksi bioetanol dengan bahan baku kulit cempedak yang dihasilkan dari fermentasi dengan bantuan mikroba S.cerevisiae. Selain itu juga untuk mengetahui jumlah kadar 
etanol dan kualitas dari hasil produksi bioetanol kulit cempedak. Luaran yang dihasilkan dari pemanfaatan kulit cempedak ini diharapkan mampu menjadi solusi bagi kelangsungan bumi dan mengurangi ketergantungan masyarakat akan penggunaan bahan bakar fosil dengan beralih pada bahan bakar yang lebih ramah lingkungan.

\section{METODE PENELITIAN}

Seluruh aspek dari penelitian ini yang meliputi pendahuluan sampai pada hasil dan pembahasan didapatkan melalui studi pustaka melalui beberapa sumber yang terdapat pada situs internet. Studi pustaka yang digunakan meliputi studi jurnal yang diunggah di website, artikel, dan surat kabar elektronik.

\section{HASIL DAN PEMBAHASAN}

Pada pembuatan bioetanol yang memanfaatkan kulit cempedak ini terdiri dari beberapa hal yang perlu dipersiapkan sebelumnya yaitu meliputi persiapan alat dan bahan, bahan baku, dan proses berlangsungnya fermentasi.

\section{A. Persiapan Alat dan Bahan}

Alat yang digunakan dalam penelitian ini terdiri dari sudip, wadah, oven, $\mathrm{pH}$ meter, pipet tetes, termometer, dan pengaduk gelas. Sementara untuk bahanbahan yang diperlukan yaitu kulit cempedak, mikroba Saccharomyces cerevisiae, akuades, dan kertas saring.

\section{B. Bahan Baku}

Kulit cempedak dicuci, dibersihkan, dan dibuang arinya kemudian dipotong berukuran kecil dan dicuci kembali untuk memastikan kulit cempedak yang akan difermentasi telah bersih. Langkah selanjutnya kemudian mengeringkan kulit cempedak dengan bantuan panas matahari atau jika ingin lebih cepat dan mudah dapat dikeringkan dengan cara dioven. Pengeringan ini dimaksudkan agar kandungan air dalam kulit cempedak berkurang, namun perlu diperhatikan agar jangan sampai terlalu kering. Jika kulit cempedak terlalu kering tentu akan menyulitkan ketika proses penyaringan karena kandungan airnya sudah tidak ada lagi. Kulit cempedak yang telah setengah kering kemudian diblender 
bersamaan dengan akuades hingga menjadi bubur yang halus dan disaring menggunakan kertas saring untuk mendapatkan filtratnya.

\section{Fermentasi}

Filtrat yang telah dihasilkan dari proses persiapan bahan baku yang dilakukan sebelumnya kemudian difermentasikan dengan bantuan mikroba Saccharomyces cerevisiae dengan didiamkam pada ruangan kedap cahaya selama kurang lebih empat hari. Pada proses ini tentu sangat diperlukan optimalisasi dalam mewujudkan habitat yang sesuai bagi berkembangnya mikroba. Lingkungan hidup yang cocok tentu akan mempermudah fermentasi dan menghasilkan etanol yang diinginkan.

Dari penelitian yang dilakukan dapat diperkirakan akan diketahui karakteristik kulit cempedak yang mengalami perubahan setelah dilakukannya proses fermentasi. Sebelum proses fermentasi dilakukan, struktur kulit cempedak masih mulus dan tidak pecah. Namun setelah proses fermentasi dilakukan, struktur kulit cempedak berubah yaitu ditandai dengan robeknya serat kulit cempedak yang diteliti. Dari penelitian, juga diperkirakan akan ditemukan hubungan antara berat cempedak dengan kandungan karbohidrat gula yang diperoleh, yaitu seperti tertera pada tabel 1

Tabel 1. Tabel Hubungan antara Berat Kulit Cempedak dengan Kandungan Gula yang diperoleh (H, Safitri, \& Putra, 2015)

\begin{tabular}{ccc}
\hline No & Berat Cempedak (\% w/v) & Kadar Gula Total $(\%)$ \\
\hline 1. & 2,5 & 5 \\
2. & 5 & 14 \\
3. & 7,5 & 15 \\
4. & 10 & 16 \\
\hline
\end{tabular}

Dari tabel diatas diketahui bahwa hubungan antara berat cempedak dan kadar gula adalah berbanding lurus yaitu semakin banyak kulit cempedak yang digunakan maka kadar gula yang terkandung pun semakin banyak. Dari proses fermentasi selama kurang lebih empat hari, didapatkan hasil bioetanol dengan kadar berkisar antara $0,5-1 \%$. Bioetanol ini dapat menjadi campuran dalam bahan bakar fosil misalnya premium sekalipun kadarnya hanya sedikit. Bahkan menurut penelitian dan pengujian yang dilakukan oleh Yolanda J. Lewerissa, Dosen Jurusan Mesin, 
Politeknik Katolik Saint Paul Sorong ditemukan fakta bahwa performa mesin yang menggunakan bahan bakar campuran lebih baik daripada yang hanya menggunakan bahan bakar murni.

\section{KESIMPULAN}

Berdasarkan dari metode dan hasil penelitian yang telah dijabarkan, diperkirakan akan didapatkan hasil bioetanol dengan kadar berkisar antara 0,51\%. Kadar bioetanol ini dapat menjadi campuran dalam bahan bakar fosil, misalnya premium yang menurut penelitian yang telah dilakukan sebelumnya ternyata memiliki keunggulan dalam meningkatkan performa mesin. Bioetanol berbahan dasar kulit cempedak ini diharapkan dapat menjadi solusi di masa depan utamanya dalam pemanfaatan limbah hayati untuk keberlangsungan hidup bumi.

\section{DAFTAR PUSTAKA}

Hasbianto, Agus., \& Noor, Aidi. (2014). Cempedak Bayan: Si Jumbo dari Balangan. Badan Litbang Pertanian Kalimantan Selatan.

Jeffries, T.W. and Jin, Y.S. (2000). Ethanol and thermotolerance in the bioconversion of xylose by yeasts. Adv. Appl. Microbiology, 47: 221-268.

Karim, A. dan Sutjahjo, D. H. (2013). Uji Kinerja Mesin 4 Langkah Berbahan Bakar Bioethanol Dari Limbah Kulit Jerami Nangka Sebagai Campuran Premium. Jurnal Teknik Mesin, 1.

Khairani, R. (2007). Tanaman Jagung Sebagai Bahan Bio-fuel http://www.Macklintmip.unpad. net/ Biofuel/ Jagung/ Pati.pdf. diakses tanggal 2 Desember 2019.

Lewerissa, Y. J. Pengaruh Campuran Bahan Bakar Mesin dan Etanol terhadap Prestasi Mesin Bensin. diakses pada 4 Desember 2019. https://media.neliti.com/media/publications/256921-pengaruh-campuranbahan-bakar-bensin-dan-2105d4cb.pdf

Madigan, M.T., Martinko, J.M., Dunlap, P.V., dan Clark, D.P. 2008. Biology of Microorganisms 12th edition. Pearson, San Francisco.

Muthohar, A. (2012). Pemanfaatan Limbah Kulit/Jerami Nangka (Artocarpus Heterophyllus) Sebagai Bahan Bakar Alternatif (Bioethanol). Surabaya: Universitas Negeri Surabaya

Novia, N., Windarti, A., dan Rosmawati, R. (2014). Pembuatan Bioetanol dari Jerami Padi dengan Metode Ozonolisis-SSF. Jurnal Teknik Kimia 20(3): 38-48.

Safitrie, Gusti Safriana., Safitri, E. M., \& Putra, M. D. (2015). Pemanfaatan Kulit Cempedak Sebagai Bahan Baku Pembuatan Bioetanol dengan Proses 
Fermentasi Menggunakan Saccharomyces Cereviseae. Banjarbaru: Universitas Lambung Mangkurat.

Zainuddin, Hasan. (2015). Kalsel Kebanjiran Buah Cempedak. Antara News Kalimantan Selatan. 